\title{
Percepções sobre o Programa Bolsa Família na sociedade brasileira
}

\author{
Henrique Carlos de Oliveira de Castro \\ Centro de Pesquisa e Pós-Graduação sobre as Américas - CEPPAC \\ Universidade de Brasília \\ Maria Inez Machado Telles Walter \\ DATAUnB - Pesquisas Sociais Aplicadas \\ Universidade de Brasília \\ Cora Maria Bender de Santana \\ DATAUnB - Pesquisas Sociais Aplicadas \\ Universidade de Brasília \\ Michelle Conceição Stephanou \\ DATAUnB - Pesquisas Sociais Aplicadas \\ Universidade de Brasília
}

\begin{abstract}
Resumo: $\mathrm{O}$ artigo trata de percepções da sociedade brasileira sobre o Programa Bolsa Família (PBF) a partir de uma pesquisa realizada em amostra da população. A pesquisa indicou que a população reconhece o Programa e entende que ele está sendo utilizado de forma adequada, mesmo considerando problemas em sua execução. Houve uma importante diferença entre a opinião daqueles que conhecem beneficiários em relação àqueles que não conhecem, sendo que os primeiros se manifestaram de forma mais positiva em relação aos resultados e mais cautelosos em relação às críticas, conclui que o PBF adquiriu legitimidade junto à sociedade brasileira dado o nível de conhecimento da política e mesmo de apoio à sua existência e argumenta sobre a importância de buscar e considerar a opinião da sociedade como importante elemento de avaliação de políticas públicas.
\end{abstract}

Palavras-chave: avaliação de políticas; opinião pública; política social; Bolsa Família; imagem institucional

Abstract: The paper is about perceptions of Brazilian society concerning the cash transfer program Bolsa Família of Brazilian government obtained in a national survey. It indicated that population recognizes the program and understands that it is being used in an appropriated way, even though considering problems in its execution. Important differences occurred in the opinion of those who knew beneficiaries comparing with those who didn't. The first group manifested positive opinion and criticized less then the second. The paper concludes that the program acquired legitimacy in the Brazilian society, considering the knowledge of this policy and supporting its existence. It argues for the importance of searching and considering the public opinion as a fundamental element of public policy assessing.

Keywords: policy assessing; public opinion; social policy; cash transfer; institutional image

OPINIÃO PÚBLICA, Campinas, vol. 15, nº 2, Novembro, 2009, p.333-355 


\section{Introdução}

A política pública é a revelação da ação do Estado em determinado período histórico, estabelecida por um governo constituído por um "conjunto de programas e projetos que parte da sociedade (políticos, técnicos, organismos da sociedade civil e outros) propõe para a sociedade como um todo" (HÖFLING, 2001, p.2).

Políticas sociais constituem um subconjunto das políticas públicas relacionado a ações que determinam o padrão de proteção social implementado pelo Estado e se relacionam à distribuição de benefícios sociais para reduzir as desigualdades estruturais decorrentes da trajetória do desenvolvimento socioeconômico, usualmente nas áreas de educação, saúde, previdência, habitação, saneamento etc., e executadas sob a responsabilidade do Estado.

Na tradição marxista, Höfling (2001) destaca a definição de Claus Offe (1984), para quem "política social é a tentativa do Estado em transformar de forma duradoura o trabalho não assalariado em trabalho assalariado" (OFFE, 1984, p.15). Essa necessidade surgiria da desorganização e da mobilização da força de trabalho decorrente da industrialização capitalista, que teria provocado a destruição massiva e contínua das formas de trabalho e de subsistência habituais criando, consequentemente, o mercado de trabalho. O problema da inserção da força de trabalho não se resolveria por si, mas pela ação do Estado qualificando permanentemente a mão-de-obra para o mercado, e mantendo sob controle a parcela da população excluída do processo produtivo.

$\mathrm{Na}$ visão liberal, por outro lado, o Estado teria como função promover as condições para o exercício da competitividade individual, considerando a intervenção estatal como um risco e as políticas sociais - ações do Estado com o objetivo de regular os desequilíbrios gerados pelo desenvolvimento da acumulação capitalista - entraves ao desenvolvimento, e responsáveis pelas crises sociais, pois ameaçaria os interesses e as liberdades individuais, inibindo a livre iniciativa e a concorrência e bloqueando mecanismos que o próprio mercado seria capaz de reequilibrar.

A noção de solidariedade surge no final do século XIX como opção à regra de justiça liberal (MAGALHÃES, 2001), elevando a importância da coesão social, do pertencimento e da inter-relação natural entre indivíduos. O bem-estar geral depende da participação de todos, e o Estado adquire papel não mais residual, mas de "responsável pela materialização da solidariedade através de mecanismos e estratégias próprios de repartição dos bens e serviços sociais" (MAGALHÃES, 2001, p.3). A solidariedade é uma das bases da instituição dos sistemas de proteção social que se desenvolveram durante o século XX e entraram em colapso nas últimas décadas, como muito já se discutiu. Compõe também a base da

\footnotetext{
${ }^{1}$ Ver, por exemplo, Rosanvallon (1997;1998).
} 
conceituação e construção das políticas sociais que se impuseram como forma de prevenir ou remediar a convulsão social. Ultimamente, diante da crise dos programas de proteção social, o risco de desagregação da solidariedade social somou-se às preocupações com a dissolução do tecido social.

No contexto de crescente desqualificação social, cada vez mais multifacetada, Magalhães lembra que o conceito de exclusão ganha força na discussão sobre a incapacidade de os indivíduos suprirem suas próprias necessidades, "tornando-se um perigo para si mesmos e para o restante da sociedade" (MAGALHÃES, 2001, p. 8). Segundo a autora, trata-se de outra forma de abordar a pobreza, não como um problema individual, mas coletivo e inserido nas sociedades industriais modernas - urbanização desordenada, desigualdade e segregação social, inadaptações escolar e profissional e violência. Um dos principais fundamentos do conceito foi o agravamento do desemprego, da ruptura dos laços sociais e o consequente enfraquecimento da coesão e da solidariedade após os anos 1980. Desse modo, as compensações financeiras entraram em pauta como forma de reduzir o problema em situações específicas.

Conforme Rosanvallon, essas compensações foram a tentativa de saldar uma dívida social. "Uma concepção muito ampla da reparação dos prejuízos serve, neste caso, de substituto de um exercício político de solidariedade. (...) O indivíduo pode pretender uma compensação ao se fazer reconhecer como vítima" (ROSANVALLON, 1998 , p. 63). Tal concepção legitima o benefício das transferências públicas como direito social. E, sendo assim, a solidariedade dá lugar à tolerância; a igualdade cede espaço à imparcialidade. A boa prática social passa a ser a convivência pacífica com as diferenças e não mais a que assegura a sua inserção. Em consequência, esse direito social termina por referendar a exclusão. Para não perder de vista o necessário avanço social, o autor reafirma a necessidade do empenho na ideia do direito ao trabalho, e não no direito a uma renda. Com isso, a inserção pelo trabalho foi apontada por Rosanvallon (1998, p.104) como a pedra angular da luta contra a exclusão.

O conceito de desafiliação proposto por Castels surge como alternativa à rígida dicotomia incluídos/excluídos. Agregando a participação em redes de sociabilidade e em sistemas de proteção social, o conceito de Castels é considerado como a forma de perceber a existência de posições intermediárias e também as múltiplas e alternadas trajetórias de integração e exclusão. Seria uma leitura multidimensional e dinâmica da instabilidade social, pois a desigualdade é algo que muda de perfil ao longo do tempo.

Refletindo isso, as políticas sociais passaram, pois, a tratar da inclusão - no emprego, na moradia, na escola, no sistema de saúde. Teoricamente, emerge a 
necessidade de criar e manter mecanismos de integração social, o que se daria pela construção de parcerias com entidades civis e comunitárias.

Trata-se aqui, pelo lado do Estado, da reedição de um antigo paradoxo. 0 Estado, alheio e unilateral, não foi capaz de impedir a corrosão dos laços sociais. Entretanto, espera-se que a recondução das políticas sociais não só resgatem, mas que criem esses laços e essa parceria. Enfim, que seja o remédio para a doença que ajudou a incubar. Por outro lado, é também a resposta a uma nova demanda social que se impõe, sob o risco de perder o controle sobre a iminência da convulsão social.

Basicamente, os programas de transferência de renda podem ser enquadrados em dois tipos: "renda básica de cidadania" e "renda mínima garantida" (VANDERBORGHT \& PARIJS, 2006). O primeiro tipo - renda básica de cidadania - é a transferência regular de dinheiro, pelo Estado, a todos os cidadãos, sem qualquer restrição social ou econômica. O exemplo mais conhecido é o do estado do Alasca, nos Estados Unidos, que introduziu, a partir de 1976, um programa de distribuição, para todos os cidadãos, de cerca de $6 \%$ do seu PIB (a fonte dos recursos, em grande parte, é a destinação de $50 \%$ dos royalties provenientes da exploração do petróleo no estado). O Programa Bolsa Família, por sua vez, é uma variante do segundo tipo, a renda mínima garantida. Programas de renda mínima garantida diferenciam-se de programas de renda básica de cidadania por serem focalizados na parcela mais pobre da população, além de não exigirem qualquer tipo de contrapartida. O Programa Bolsa Escola, nesse sentido, é uma variante de programa de renda mínima garantida, na medida em que fazem parte da sua concepção contrapartidas por parte dos beneficiários.

As políticas que incorporam a ideia de contrapartida são uma forma de combinar indenização e inserção social com o engajamento pessoal dos beneficiários (MAGALHÃES, 2001). O Estado permanece como elemento-chave para a definição dessas políticas². Em países como o Brasil, na visão da autora, a desagregação, a desigualdade e a erosão da cidadania participativa impõem a busca de novas formas de intervenção pública. A tarefa fundamental é reconstruir um perfil de convivência menos ameaçado.

$\mathrm{O}$ pacto com a sociedade civil tem ocorrido em duas frentes. Por um lado, o terceiro setor, também chamado de setor público não-estatal e de organizações da sociedade civil, representa a legitimação da prestação de serviços públicos na esfera privada. É uma das facetas da redução do Estado, da descentralização e setorialização de serviços de interesse público. Por outro, o naco de políticas sociais de inclusão que se mantêm na esfera pública é seletivo, focalizado e atua principalmente junto aos mais pobres dentre os pobres, na forma de políticas

\footnotetext{
2 Segundo Draibe (2002), no Brasil, o Estado nunca se afastou do campo das políticas sociais.
} 
compensatórias, de transferência condicional de renda, caso do Programa Bolsa Família (PBF).

Em vista da incompatibilidade entre os ajustes estruturais da economia e os investimentos sociais do Estado legitimada pelo ideário neoliberal, o discurso da cidadania e dos direitos sociais foi substituído pelo discurso humanitário da filantropia. As políticas sociais adquiriram então um perfil "despolitizado, privatizado e refilantropizado" (YASBEK, 2004, p.3), fundado na solidariedade social, em componentes éticos e humanitários.

$\mathrm{Na}$ sociedade, por outro lado, a discussão acadêmica sobre o lugar e o papel das políticas de transferência de renda parece não se dar da mesma forma. É improvável que a população exerça a problematização e a reflexão a partir de fundamentos teóricos e de articulação dos problemas sociais no contexto mais amplo. A discussão ocorre na sociedade com base na comunicação de massa, com todas as limitações inerentes a esses canais, principalmente a superficialidade e o reducionismo. Essa afirmação não constitui, absolutamente, uma crítica à comunicação de massa em si, pois não se podem exigir abordagens complexas e, portanto, pouco claras à maioria das pessoas, como são os estudos fundamentados em teorias ou empiria científica.

A mídia chama a atenção do público e faz pressão política sobre temas em particular. As coberturas dão o tom de interpretação e definem o caráter das questões como econômicos ou políticos, sociais ou pessoais, radicais ou conservadores. A seleção dos temas tem motivações difusas e as formas de noticiar possuem implicações sobre a mensagem que chega ao público. Esses vieses fazem da mídia, portanto, um mediador imperfeito para a opinião pública (HOWLETT, 2000). Da mesma forma, nos grupos sociais de interesse específico e nos partidos políticos também há dificuldades de transmitir a opinião pública. Suas demandas também sofrem vieses em virtude de prioridades inerentes às respectivas plataformas.

Assim, a ideia de que uma parcela da população está recebendo numerário é comumente classificada como esmola ou assistencialismo, e teria como consequência uma acomodação dos beneficiários em relação ao trabalho, o chamado "efeito-preguiça"3. Além disso, a reiterada divulgação de casos de pessoas que não fariam jus ao benefício, até mesmo a inclusão fraudulenta ${ }^{4}$, com certeza contribuem para sedimentar essas rejeições.

Há críticas relacionadas ao uso eleitoral do PBF, que ressaltam o caráter de marketing político - no mau sentido (MOURA, 2007). Deve-se ter em conta que qualquer ação governamental, em todas as esferas, potencialmente constitui um

\footnotetext{
${ }^{3}$ Ver, por exemplo, Clemente (2006), Pinto \& Meneses (2008) e Moisés (2008).

4 Ver exemplo em Supervisor (2004), MPF (2007).
} 
tema de marketing político, pois revela o exercício das prioridades divulgadas durante a disputa eleitoral. Mas não necessariamente o uso político implica em iludir a sociedade com propostas que não correspondam ao que de fato será feito.

Seria esperarado, portanto, que o Bolsa Família tivesse uma imagem predominantemente negativa junto à população. Seja por não concordar com políticas de repasse de dinheiro a pessoas - a partir do princípio de que não se deve dar o peixe, mas ensinar a pescar -, seja pela perspectiva de que o dinheiro público será desviado por fraudes na inclusão indevida de pessoas, seja pelo incentivo à natalidade para perpetuar o benefício ${ }^{5}$.

Este artigo tem como propósito demonstrar empiricamente que essas críticas convivem com a percepção de que os principais objetivos do PBF estão sendo atingidos, incluindo o principal, que é a redução da pobreza. Isso está feito com base em uma amostra de 6.001 entrevistados na população brasileira ${ }^{6}$.

\section{Dados sobre percepções acerca do Programa Bolsa Família}

As análises qualitativas que antecederam a pesquisa amostral sinalizaram que o grau de conhecimento do Programa Bolsa Família era bastante amplo. De fato, a quantidade de pessoas que não souberam responder às perguntas sobre 0 Programa foi menor que $1 \%$.

A primeira indagação na pesquisa era se o Programa fazia diferença para o Brasil, se trazia mais coisas boas ou mais coisas ruins. No país, quase três a cada quatro respondentes (72\%) consideraram que o Bolsa Família traz mais coisas boas para o país. Essa posição variou significativamente nas regiões ${ }^{7}$. O Nordeste registrou o menor percentual de entrevistados que afirmaram que o Programa não faz diferença (10\%), enquanto nas outras regiões esse percentual ficou na faixa de $13 \%$ a $16 \%$. Inversamente, os maiores percentuais de pessoas que consideraram que o Bolsa Família traz mais coisas ruins ocorreu no sul (17\%) e no centro-oeste (13\%). Mesmo assim, foi majoritária a percepção positiva em todas as regiões brasileiras $^{8}$.

\footnotetext{
${ }^{5}$ Essas críticas sintetizam percepções captadas em quinze grupos focais realizados em sete capitais brasileiras nas regiões Sul, Sudeste e Centro-Oeste, no âmbito da Pesquisa "Percepção sobre os Programas Federais", 2008 (ver descrição no Anexo).

6 Pesquisa "Percepção sobre os Programas Federais", 2008. Ver descrição no Anexo.

7 Teste de associação de Qui-quadrado $\left(\chi^{2}=160,232 ; \mathrm{P}<0,001\right)$.

8 Foram feitas análises dos cruzamentos dos resultados da Figura $1 \mathrm{com}$ as variáveis sociodemográficas sexo, idade, cor/etnia, renda e escolaridade. A percepção de que o Bolsa Família traz mais coisas boas para o Brasil foi majoritária em todas as categorias das variáveis demográficas. Não foi detectada associação significativa com sexo $\left(\chi^{2}=1,499 ; P=0,682\right)$. As demais variáveis foram significativamente associadas com a percepção geral sobre o Bolsa Família. No caso da idade $\left(\chi^{2}=31,635 ; P<0,001\right)$, de $13 \%$ a $14 \%$ em todas as classes consideraram que o Programa não faz diferença para o Brasil, enquanto a reprovação aumentou proporcionalmente à idade, ou seja, os mais velhos foram mais recorrentes em considerar que o Bolsa Família traz mais coisas ruins para o Brasil (9\% entre as pessoas de 18 a 24
} 
Figura 1

Percepção geral sobre o Programa Bolsa Família por região (\%)

Brasil, 2008

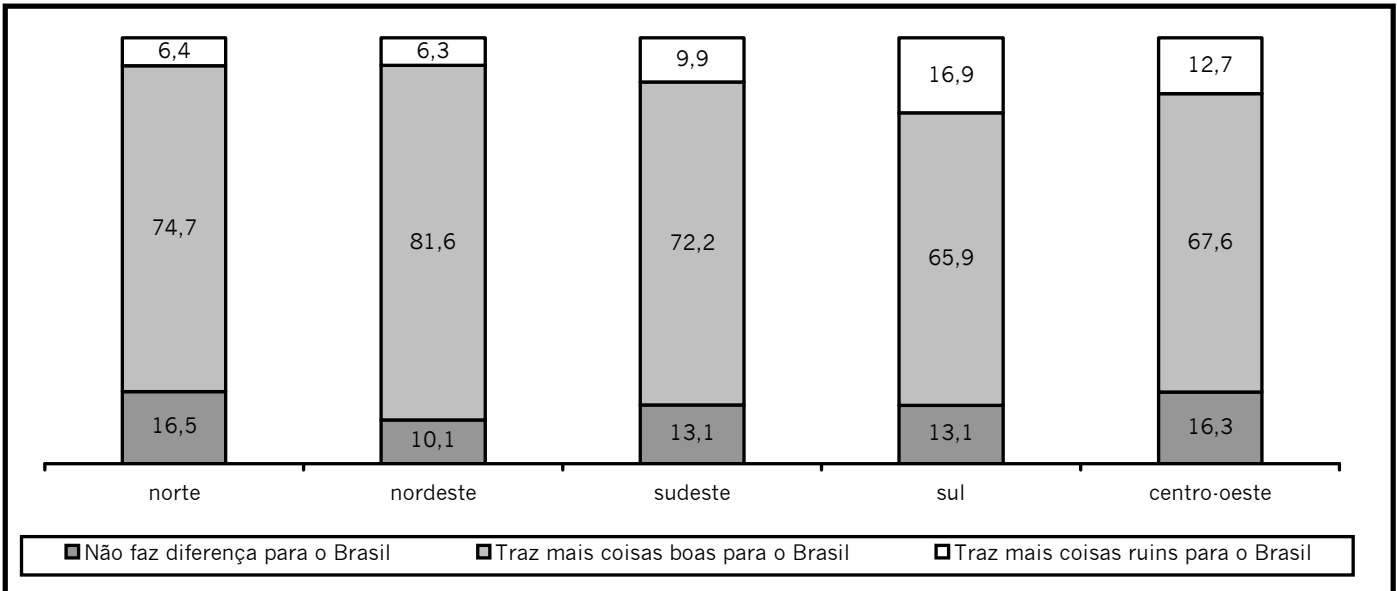

Fonte: DATAUnB

Essa avaliação também foi significativamente associada ao fato de conhecer ou não alguém que é ou foi beneficiário do Programa Bolsa Família9: Aqueles que conhecem algum beneficiário do Bolsa Família consideraram que o Programa traz mais coisas boas para o Brasil (77\%). Inversamente, os que não conhecem nenhum beneficiário, mostraram maior tendência a considerar que o Programa não faz diferença (18\%) ou traz mais coisas ruins para o Brasil (16\%) (Figura 2).

anos até $12 \%$, entre os de mais de 60 anos). A variável cor/etnia também influenciou essa avaliação $\left(\chi^{2}=\right.$ 105,478; $\mathrm{P}<0,001$ ): $14 \%$ dos brancos e $11 \%$ dos amarelos consideraram que o Bolsa Família traz mais coisas ruins, e $7 \%$ dos negros e também dos pardos tiveram a mesma percepção. A desaprovação do Programa, pela percepção de que traz mais coisas ruins para o Brasil, cresce proporcionalmente à renda. Entre os de menor renda, 5\% desaprovam o Bolsa Família, percentual que cresce até $26 \%$ entre os de renda maior que 10 salários mínimos. Por fim, quanto maiores os graus de escolaridade, mais desaprovação $\left(\chi^{2}=214,893 ; P<0,001\right)$. 0 percentual de desaprovação foi de $5 \%$, entre as pessoas sem instrução, até $24 \%$, entre os de nível de escolaridade superior.

9 Teste de associação de Qui-quadrado $\left(\chi^{2}=383,587 ; \mathrm{P}<0,001\right)$. 


\section{Figura 2}

\section{Percepção geral sobre o Programa Bolsa Família por região (\%)}

Brasil, 2008

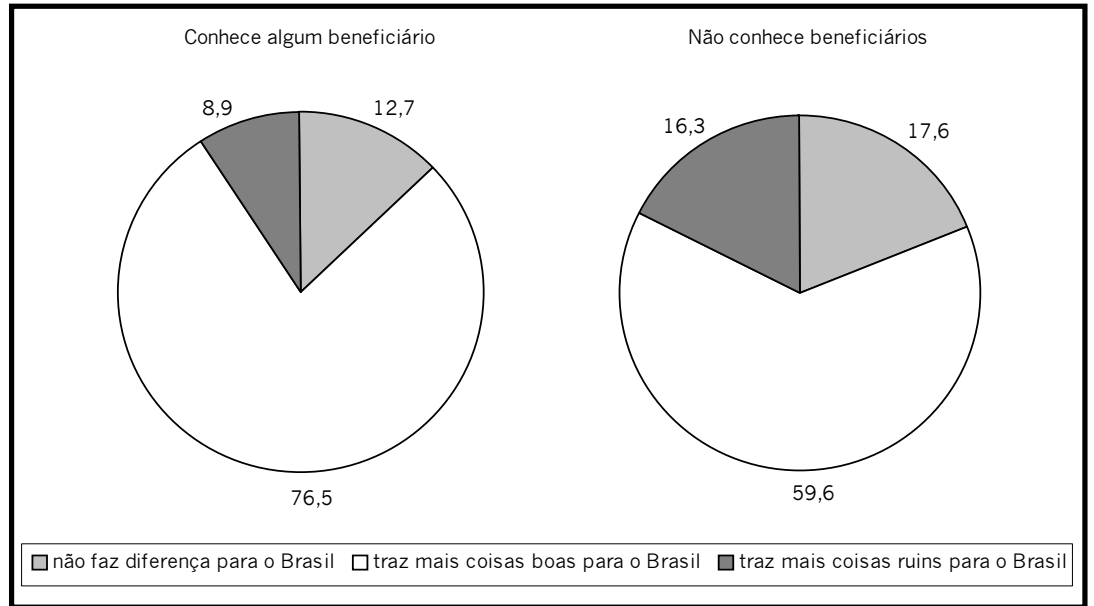

Fonte: DATAUnB

O questionário incluiu uma bateria de afirmações sobre o Bolsa Família para verificar em que medida a população concorda que os objetivos estão sendo alcançados, se haveria efeitos positivos e melhoria na vida de pessoas, famílias e comunidades, sobre a forma como os recursos estão sendo utilizados pelos beneficiários e, finalmente, em que medida há concordância com críticas comuns ao Programa.

A Tabela 1 mostra que o objetivo de manutenção das crianças na escola foi o que a população mais frequentemente percebeu (83\%). Por outro lado, a eficácia na melhora da saúde das gestantes, embora majoritária, foi a que apresentou menor frequência de concordância (64\%), o objetivo de ajudar no combate à pobreza também foi menos assinalado (65\%). 
Tabela 1

Percepção sobre a consecução dos objetivos do Programa Bolsa Família (\%) Brasil, 2008

\begin{tabular}{|l|c|}
\hline $\begin{array}{c}\text { Concordância com o consecução dos objetivos do } \\
\text { Programa Bolsa Família }\end{array}$ & $\begin{array}{c}\text { Sim/ Tende a } \\
\text { concordar }\end{array}$ \\
\hline Ajuda a combater a pobreza no Brasil & 65 \\
\hline Ajuda a manter as crianças na escola & 83 \\
\hline Ajuda a melhorar a educação das crianças & 74 \\
\hline Ajuda a combater o trabalho infantil & 73 \\
\hline Ajuda a melhorar a saúde das gestantes & 64 \\
\hline Ajuda a melhorar a saúde das crianças & 72 \\
\hline
\end{tabular}

Fonte: DATAUnB

O fato de conhecer ou não algum beneficiário associou-se a maior concordância com todas as afimações, por exemplo, os que conhecem algum beneficiário concordam mais frequentemente que o Programa ajuda a combater a pobreza: $69 \%$ dos entrevistados que conhecem algum beneficiário e $52 \%$ dos que não conhecem ${ }^{10}$; resultados semelhantes mostravam-se em relação aos demais itens da Tabela 1, sendo sempre maior o percentual de concordância entre os que conhecem algum beneficiário (Figura 3).

${ }^{10}$ Associação significativa segundo o teste de associação de Qui-quadrado $\left(\chi^{2}=111,485 ; P<0,001\right)$. 
Figura 3

Concordância com os objetivos do Programa Bolsa Família (\%) Brasil, 2008

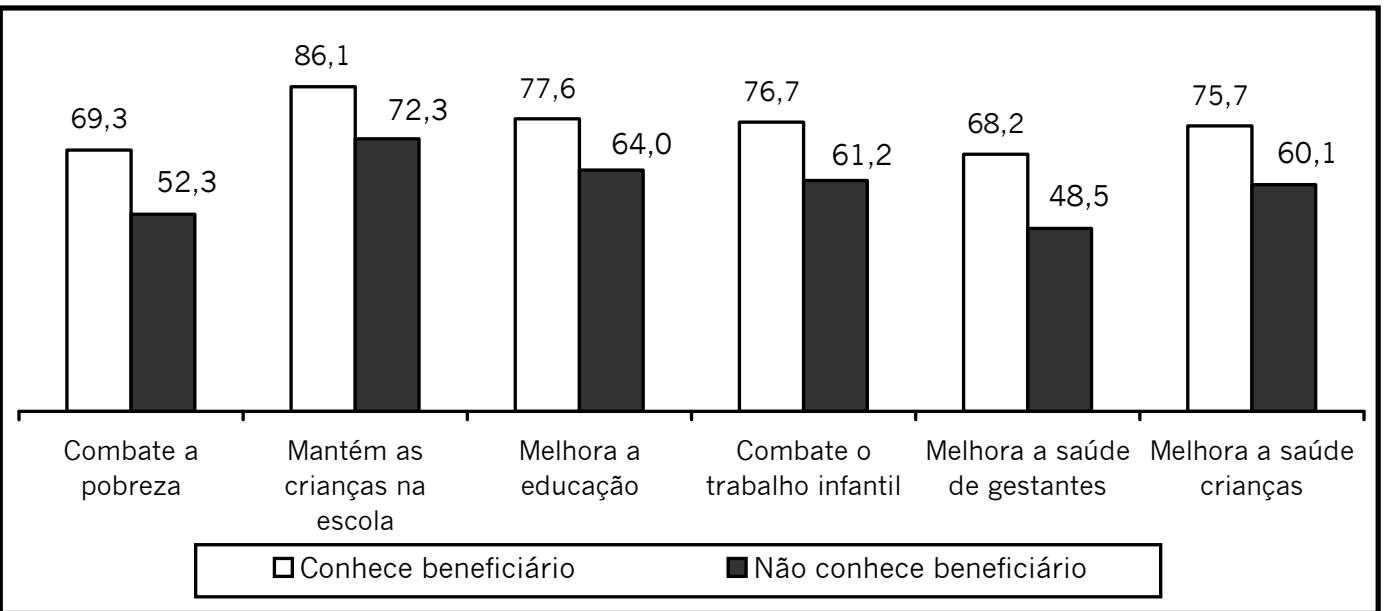

Fonte: DATAUnB

Dos respondentes, 44\% concordaram com todas as afirmações e $9 \%$ discordaram de todas elas. Ao verificar com quantas das seis afirmativas as pessoas concordaram, constata-se que quem conhece algum beneficiário concordou com quatro a cinco afirmatições. Entre os que não conhecem beneficiários, a quantidade média foi de 3,6. Essas médias são significativamente distintas ${ }^{11}$, indicando que o grau de concordância de que os objetivos do Programa Bolsa Família estão sendo atingidos está relacionado ao conhecimento dele pelos beneficiários.

Com relação à percepção sobre melhorias decorrentes do Programa Bolsa Família na vida das pessoas, das famílias, das comunidades e da população, os dados indicam que a concordância foi de pelo menos $68 \%$, exceto em relação a melhorias para toda a população (Tabela 2).

${ }^{11}$ Teste de diferença entre duas médias (T-Student = 14,292; $\mathrm{P}<0,001$ ). 
Tabela 2

Percepção sobre melhorias decorrentes do Programa Bolsa Família (\%) Brasil, 2008

\begin{tabular}{|l|c|}
\hline \multicolumn{1}{|c|}{$\begin{array}{c}\text { Concordância com melhorias decorrentes do } \\
\text { Programa Bolsa Família }\end{array}$} & $\begin{array}{c}\text { Sim/ Tende a } \\
\text { concordar }\end{array}$ \\
\hline É bom para melhorar a vida das pessoas & 72 \\
\hline É bom para melhorar a vida das famílias & 75 \\
\hline É bom para melhorar a vida das comunidades & 68 \\
\hline É bom para melhorar a vida de toda a população brasileira & 56 \\
\hline
\end{tabular}

Fonte: DATAUnB

No caso da percepção das melhorias, também foi significativa a associação com o fato de conhecer ou não algum beneficiário, sendo sempre maiores os percentuais de concordância entre os que conhecem.

Figura 4

Concordância com as melhorias decorrentes do Programa Bolsa Família (\%)

Brasil, 2008

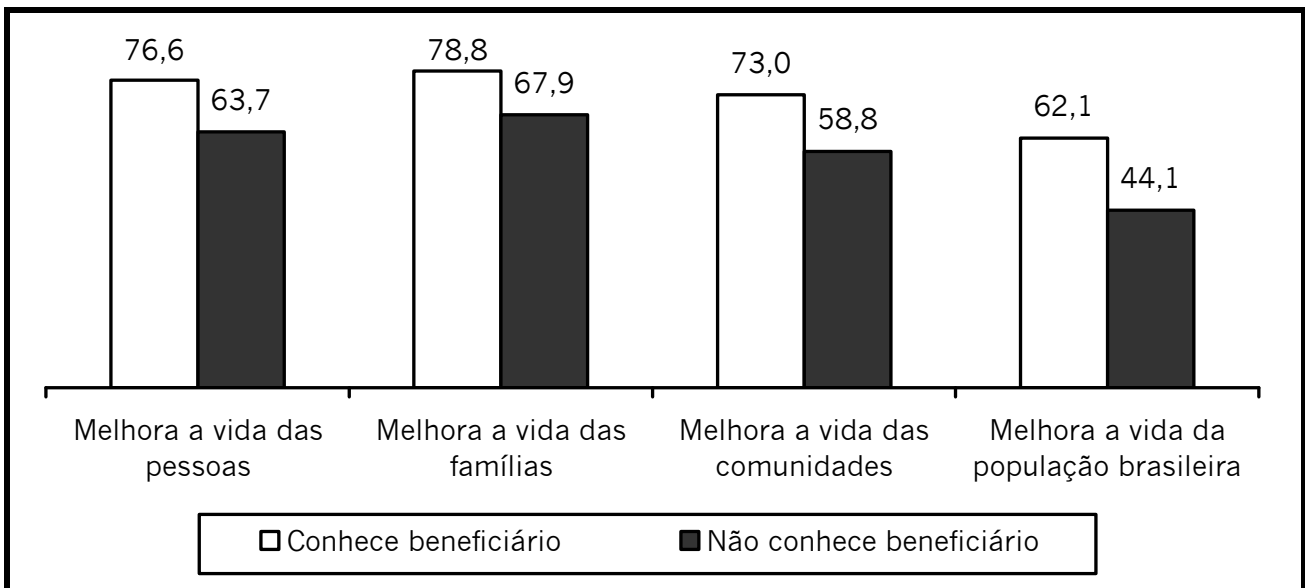

Fonte: DATAUnB 
No caso das melhorias, $51 \%$ concordaram com todas as quatro afirmações, enquanto $20 \%$ discordaram de todas. Mais uma vez, foi significativa a diferença entre a quantidade média de afirmativas com as quais aqueles que conhecem beneficiários e os que não conhecem concordaram ${ }^{12}$. A média entre os que conhecem foi de 2,8 e entre os que não conhecem foi de 2,2.

Sobre o uso do benefício, o mais frequentemente percebido foi a compra de mais alimentos (79\%) e de mais material escolar (75\%). Os itens sobre a aquisição de mais artigos de uso pessoal e de mais utensílios para o lar foram assinalados por aproximadamente $60 \%$ dos entrevistados, como demonstra a Tabela 3.

Tabela 3

Percepção sobre o uso do benefício do Programa Bolsa Família (\%) Brasil, 2008

\begin{tabular}{|l|c|}
\hline \multicolumn{1}{|c|}{$\begin{array}{c}\text { Concordância com os usos do benefício do } \\
\text { Programa Bolsa Família }\end{array}$} & $\begin{array}{c}\text { Sim/ Tende a } \\
\text { concordar }\end{array}$ \\
\hline Faz as pessoas poderem comprar mais alimento & 79 \\
\hline $\begin{array}{l}\text { Faz as pessoas poderem comprar mais coisas para } \\
\text { casa }\end{array}$ & 61 \\
\hline $\begin{array}{l}\text { Faz as pessoas poderem comprar mais roupas, } \\
\text { calçados objetos de uso pessoal }\end{array}$ & 58 \\
\hline $\begin{array}{l}\text { Faz as pessoas poderem comprar mais material } \\
\text { escolar }\end{array}$ & 75 \\
\hline
\end{tabular}

Fonte: DATAUnB

Mais uma vez, foi maior a concordância entre os que conhecem algum beneficiário para todos os itens; os testes de associação também foram significativos.

\footnotetext{
12 Teste de diferença entre duas médias (T-Student = 12,393; $\mathrm{P}<0,001$ ).
} 
Figura 5

Concordância com os benefícios do Programa Bolsa Família (\%)

Brasil, 2008

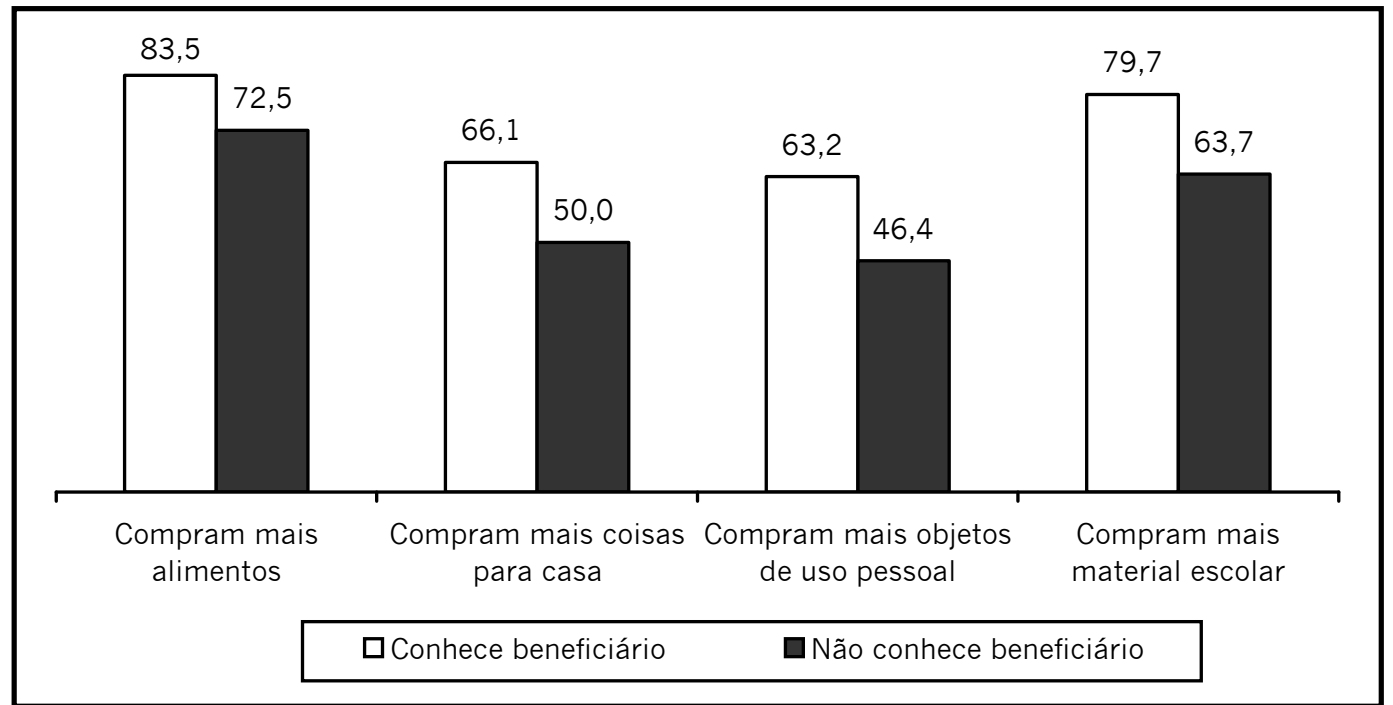

Fonte: DATAUnB

No caso do uso dos benefícios, $46 \%$ concordaram com todas as quatro afirmativas, enquanto $11 \%$ discordaram de todas. Mais uma vez, foi significativa a comparação da quantidade média de afirmativas com as quais as pessoas diferença entre as médias de concordância dos que conhecem algum beneficiário com os que não conhecem nenhum ${ }^{13}$. (a média entre os que conhecem foi de 2,9 e entre os que não conhecem foi de 2,2).

Finalmente, ao observar o quanto a população concorda com algumas das críticas que são dirigidas comumente ao Programa Bolsa Família (Tabela 4), foi verificado que a maior concordância foi com relação à fraude na inclusão, ou seja, ao fato de haver beneficiários que não fariam parte do público-alvo (82\%). A expectativa de acomodação devida à certeza de recebimento do recurso também foi bastante citada (67\%) e, em seguida, o estímulo a ter mais filhos $(56 \%)^{14}$.

\footnotetext{
13 Teste de diferença entre duas médias (T-Student = 14,557; $\mathrm{P}<0,001$ ).

14 Também no caso dessas três afirmativas, foi detectada associação significativa entre a concordância com as críticas e o fato de conhecer ou não beneficiários.
} 
Tabela 4

Percepção sobre algumas críticas comuns sobre o Programa Bolsa Família (\%) Brasil, 2008

\begin{tabular}{|l|c|}
\hline $\begin{array}{c}\text { Concordância com algumas críticas comuns sobre } \\
\text { o Programa Bolsa Família }\end{array}$ & $\begin{array}{c}\text { Sim/ Tende a } \\
\text { concordar }\end{array}$ \\
\hline Inclui pessoas que não precisam & 82 \\
\hline $\begin{array}{l}\text { Faz as pessoas se acomodarem e não quererem mais } \\
\text { trabalhar }\end{array}$ & 67 \\
\hline Faz as pessoas quererem ter mais filhos & 56 \\
\hline
\end{tabular}

Fonte: DATAUnB

Figura 6

Concordância com as críticas ao Programa Bolsa Família (\%) Brasil, 2008

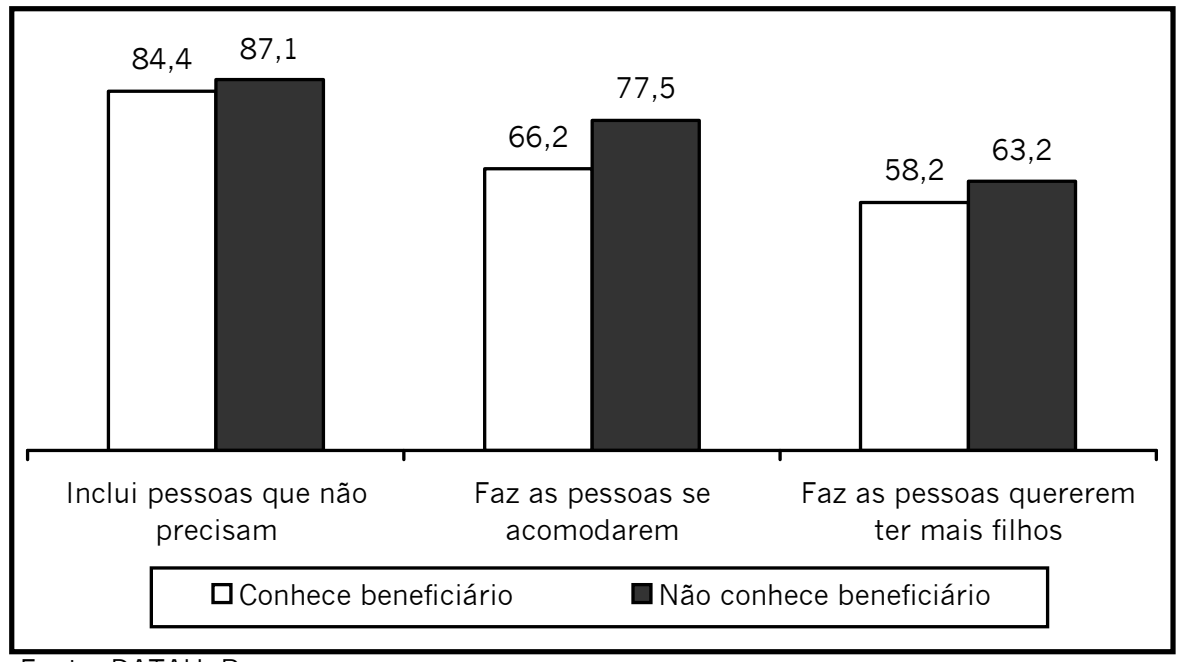

Fonte: DATAUnB

Verificando as três afirmativas em conjunto, $45 \%$ concordaram com todas e $10 \%$ discordaram de todas. A comparação da média de afirmativas com as quais as pessoas concordaram entre os que conhecem e os que não conhecem beneficiários foi mais uma vez, significativa ${ }^{15}$. Porém, nesse caso, o resultado foi invertido: entre os que não conhecem beneficiários, a concordância com as críticas foi maior. Pela Figura 6, nota-se que o resultado mais parecido foi quanto à expectativa de fraude na adesão ao Programa, alta e semelhante nos dois grupos de respondentes.

15 Teste de diferença entre duas médias (T-Student = -3,946; $\mathrm{P}<0,001$ ). 
As críticas destacadas referem-se aos tipos de burla que são recorrentemente alardeados sobre o uso do recurso público. No caso de políticas de transferência de renda, essa se relacionam a falhas na focalização e a acomodação dos beneficiários para perpetuar sua participação no programa.

As críticas relacionadas às falhas de inclusão no PBF foram classificadas por Medeiros et al (2007, p.6) como casuísticas e sem base em evidências empíricas "generalizáveis e sistemáticas", e consistem apenas em apontar famílias com renda superior ao critério e, assim, colocar em cheque todo o funcionamento dos programas. Com dados da Pesquisa Nacional por Amostra de Domicílio (PNAD), os autores afirmam que os programas estão direcionados, efetivamente, à população mais pobre do país.

Segundo Soares et al (2006), o PBF está bem focalizado, pois $80 \%$ da renda do Bolsa-Família vão para famílias abaixo da linha de pobreza (de metade de um salário mínimo per capita), e foi responsável por $21 \%$ da redução do coeficiente de Gini $^{16}$ no período 1995 a 2004. Os autores avaliaram que esta contribuição é muito grande se se levar em conta que o Programa representa menos de $1 \%$ da renda total das famílias, de acordo com os dados da PNAD. Para eles, a erradicação da pobreza e a redução substancial dos níveis de desigualdade no Brasil são metas dificilmente alcançáveis dentro de um prazo razoável sem que se recorra a mecanismos diretos de redistribuição. Os programas de transferência de renda de natureza não-contributiva são exemplos claros da adoção desse tipo de mecanismo estando, portanto, adequados ao contexto do Brasil, de combate emergencial da pobreza.

Soares (2006) acrescenta que, apesar de o PBF ter tido uma contribuição importante na redução do coeficiente de Gini no período de 1995 a 2004, foi a desconcentração dos rendimentos do trabalho o principal fator responsável pela queda do coeficiente de Gini. Isso seria positivo pela possibilidade dessa queda ser sustentável.

Senna et al (2007), entretanto, ressaltam que o critério de renda monetária combinado com uma linha de pobreza muito baixa acaba por restringir o potencial de inclusão social do Programa, com risco de não atingir segmentos sociais em situações diversas de vulnerabilidade que não podem ser reduzidas à renda.

A análise de Medeiros et al (2007) resume a percepção aqui adotada sobre os problemas de focalização. $O$ fato de a renda ser declaratória e de difícil aferição facilitam a ocorrência de distorções. Entretanto, os erros do processo de seleção são intrínsecos a um programa como esse, pois não pode haver critérios tão rígidos que o inviabilizem e que, mesmo assim, não impediriam as falhas de cobertura de

16 Indicador de desigualdade de distribuição de renda. Apresenta-se em uma escala de zero a um, sendo que zero representa a completa igualdade e um, a desigualdade absoluta na distribuição da renda. 
famílias elegíveis, nem critérios tão transigentes que levem à inclusão indevida de pessoas. Esse é um ponto de equilíbrio difícil de encontrar e sempre passível de questionamentos.

Deve-se destacar que diferentes pesquisas com amostras da população brasileira evidenciam uma constante expectativa de que as pessoas cometerão fraudes se tiverem oportunidade ${ }^{17}$. Entretanto, sem, evidentemente, negar que as fraudes estão presentes em muitos aspectos, deve-se questionar se essa generalização é justa e reflete uma realidade ou é apenas uma tradição: em que medida as ações do dia-a-dia da sociedade brasileira são atitudes antiéticas ou fraudes?

No que diz respeito às críticas segundo as quais as pessoas acomodar-seão, não se esforçarão para trabalhar e chegarão a ter mais filhos para garantir mais tempo de benefício, também não encontram confirmação empírica. Dados do IBGE citados por Medeiros et al (2007) dão conta que pessoas pertencentes a famílias que recebem benefícios trabalham tanto ou mais que as demais com renda per capita similar. No mesmo sentido, Oliveira et al (2007) concluíram que os beneficiários participaram mais do mercado de trabalho comparadamente a pessoas nas mesmas condições de vida, e detectaram forte impacto do Programa no aumento da busca por trabalho.

Medeiros et al (2007) mencionam também modelos logísticos com os dados da PNAD 2004 segundo os quais o PBF afeta negativamente o arranjo familiar que tem a mulher como chefe de família. Outros modelos familiares - mulher cônjuge e homem chefe ou cônjuge - não apresentam diferenças devidas ao benefício na inserção laboral. "O que os dados mostram é que o 'ciclo da preguiça' motivado pelas transferências é uma falácia. (...) Talvez seja desnecessário enfatizar que, geralmente, os pobres não deixam de trabalhar por decisões livres e espontâneas, e sim porque não têm emprego em condições aceitáveis" (MEDEIROS et al, 2007, p. 16).

\footnotetext{
17 Pelos dados da pesquisa do DATAUnB sobre o Programa Bolsa Família, para mais de $80 \%$ dos brasileiros o Programa inclui beneficiários indevidamente. Outro exemplo é o Estudo Eleitoral Brasileiro (ESEB) do CESOP.Unicamp/DATAUff (2002), na qual se verificou que menos da metade dos entrevistados consideraram que um eleitor deveria trocar seu voto por algum benefício que the fosse oferecido e mais de $80 \%$ afirmaram que esse eleitor aceitaria essa troca. Esses resultados indicam que a perspectiva de atitudes antiéticas é muito forte entre os brasileiros, mesmo que isso não tenha apoio em dados ou fatos concretos. Por outro lado, dados da Pesquisa Mundial de Valores (World Values Survey), realizada em mais de oitenta países a cada cinco anos desde 1981 (ver em <www.worldvaluessurvey.org>), demonstram que, no Brasil, em um escala de 1 a 10 de tolerância em relação à tomada de atitudes antiéticas (como pedir benefícios ao governo sem ter direito, evitar pagar para usar o transporte público, evitar pagar impostos e aceitar suborno para cumprir o dever) as médias foram, respectivamente, 2,72, 3,94, 3,62 e 1,86. Os resultados foram abaixo da média da escala (5,5), denotando maior intolerância do que tolerância a todas as situações apresentadas. Os dados são para 2005.
} 
Mais uma vez, as percepções de acomodação no trabalho podem ser debitadas a conceitos tradicionais, do senso comum. Contradiz isso o resultado da Avaliação Nacional do Programa Bolsa Escola Federal (CASTRO et al, 2003), que constatou que os beneficiários em todo o país consideraram que é importante frequentar a escola, principalmente, para conseguir trabalho ou emprego (49,5\%). Também foram bastante indicados os motivos de ter instrução $(46,1 \%)$ e subir ou melhorar de vida $(40,9 \%)$. Esses resultados demonstram que, mesmo para os mais pobres entre os pobres, o estudo e o trabalho apresentam-se como valores. É possível depreender dessa combinação de resultados que a melhoria de vida deverá decorrer da melhoria na instrução que reverterá, por sua vez, em maiores chances de conseguir trabalho com melhor remuneração.

A percepção de um possível aumento das taxas de natalidade entre os beneficiários também demonstra uma concepção preconcebida, tradicional e sem apoio empírico. Não foram encontrados dados que comprovem essa situação. Ao contrário, a natalidade é decrescente no Brasil, inclusive na zona rural, a que contém a população mais pobre e potencialmente candidata ao PBF.

Concluindo a análise de dados das percepções sobre o PBF na sociedade brasileira, foi feito um estudo com as afirmativas positivas sobre o Programa. Das 17 afirmativas sobre o Bolsa Família que foram lidas aos entrevistados, 14 eram positivas (de melhorias, de consecução de objetivos e uso adequado dos recursos) e as três últimas eram críticas. Tomando apenas as 14 afirmativas positivas, verificou-se que a consistência interna das respostas foi muito alta (Alfa-Cronbach $=$ 0,923). Assim, foi criado um indicador de aprovação do Programa Bolsa Família com esses 14 itens pela contagem de itens com os quais os respondentes concordaram. A comparação das médias do indicador entre as regiões brasileiras resultou em diferenças significativas ${ }^{18}$, sendo que a mais alta ocorreu no nordeste $(11,3)$. Em posições intermediárias estão o norte $(10,0)$ e o centro-oeste $(9,6)$. 0 menor grau de aprovação foi no sul e no sudeste (ambos com 8,8), como se pode observar na Tabela 5.

18 Teste de Análise de Variância $(F=70,232 ; \mathrm{P}<0,001)$. As comparações entre as médias, duas a duas, foi feita pelo teste de significância de Student-Newman-Keuls que confirmaram as diferenças (nível de significância de 0,05 ) e o ordenamento das médias conforme o texto. 
Tabela 5

Número de concordâncias com afirmações positivas sobre o Programa Bolsa Família

\begin{tabular}{|l|r|r|c|}
\hline \multicolumn{1}{|c|}{ Região } & N & Média & Desvio Padrão \\
\hline Norte & 1160 & 9,97 & 4,431 \\
\hline Nordeste & 1206 & 11,30 & 3,721 \\
\hline Sudeste & 1197 & 8,76 & 4,470 \\
\hline Sul & 1226 & 8,79 & 4,608 \\
\hline Centro-Oeste & 1212 & 9,55 & 4,402 \\
\hline Total & 6001 & 9,67 & 4,437 \\
\hline
\end{tabular}

Fonte: DATAUnB

Como mostram os dados da Tabela 5, os entrevistados, em média, concordaram com mais da metade das afirmativas positivas (as médias foram todas próximas ou superiores a nove). Assim, a despeito das críticas e dos problemas difundidos em relação ao PBF, ele é bem aceito pela população. Destaca-se como aspectos principais dessa percepção positiva, as melhorias em geral e a consecução dos objetivos, amplamente afirmados pela população. Destaca-se ainda que o conhecimento de beneficiários atua positivamente sobre a percepção geral e que isso indica que a maior informação sobre o Bolsa Família contribui para melhorar a sua imagem.

\section{Conclusão}

O presente artigo tratou de percepções da sociedade brasileira sobre o Programa Bolsa Família e, indicou basicamente que a população reconhece o Programa e entende que ele está sendo utilizado de forma adequada, mesmo considerando problemas na sua execução. Houve uma importante diferença entre a opinião daqueles que conhecem beneficiários e a daqueles que não os conhecem, sendo que os primeiros manifestaram-se de forma mais positiva em relação aos resultados e foram mais cautelosos nas críticas.

As principais conclusões deste trabalho são duas. Em primeiro lugar, mostra a legitimidade política que o PBF adquiriu junto à sociedade brasileira, dado o nível de conhecimento da política e mesmo de apoio à sua existência. Em segundo lugar, indica a importância da opinião da sociedade ser considerada como importante elemento de avaliação de políticas públicas. Não se trata apenas de verificar o nível de apoio ou rejeição a uma determinada política, mas de entender que uma análise adequada do que pensa a população poderá contribuir para verificar sua real efetividade. 
A discussão acadêmica sobre a evolução das condicionantes que culminaram no estabelecimento de políticas de transferência de renda focou em elementos como exclusão/inclusão e solidariedade social. A sociedade, entretanto, recebeu a implantação dessas políticas com muitas reservas e, nos meios de comunicação de massa, as críticas,que classificavam as políticas como assistencialistas e eleitoreiras, foram frequentes. No senso comum, a principal restrição refere-se à transferência de recursos em si, que teria efeitos deletérios sobre a inserção no mercado de trabalho, de acomodação e toda sorte de subterfúgios para manter o benefício, até mesmo gerar mais filhos. Além disso, as repetidas notícias sobre fraudes na inclusão de pessoas fora dos critérios confirmariam uma impressão, também do senso comum, de que as pessoas encontrarão meios de fraudar o Programa para desviar os recursos.

Uma pesquisa de opinião na sociedade brasileira, nesse contexto aparentemente adverso, levaria à hipótese de que as percepções seriam essencialmente negativas. Entretanto, não foi isso o que ocorreu. Os questionamentos sobre os principais objetivos, de combate à pobreza, de manutenção da criança na escola e de redução do trabalho infantil, revelaram que a população, maciçamente, concorda que estão sendo atingidos.

Outro fator que se mostrou importante para o aumento do apoio popular ao Bolsa Família foi o conhecimento de beneficiários. Provavelmente, isso propicia o acesso a mais informações sobre o Programa e, portanto, menos resistências.

Mesmo assim, foi também muito forte na sociedade a impressão de que o PBF contribui para proporcionar melhorias para a vida das pessoas, das famílias e das comunidades. Embora menos intensamente, foi ainda majoritária a percepção de que o Programa é bom para melhorar a vida de toda a população brasileira. Assim, a despeito de não dispor de dados sobre o tom das matérias jornalísticas divulgadas nos diversos meios de comunicação de massa, tem-se a impressão de que a maior parte é de críticas e de casos de fraudes e desvios. Parece, então, que essas matérias não chegam a exercer influência sobre a imagem do PBF, pois os dados indicam que predomina a aprovação e a percepção de que o Programa tem efeitos e resultados positivos.

Os dados dissonantes são os que tratam da perspectiva de fraudes, seja no campo da gestão do programa nos municípios, seja no comportamento dos beneficiários. De todos os lados haveria fraudes e estratégias de burla das regras. A pesquisa demonstrou que esse é um traço dominante na sociedade brasileira: mesmo sem evidências empíricas, os comportamentos antiéticos inexoravelmente fariam parte do caráter dos brasileiros. Salientando que o ciclo supervisãoavaliação-aprimoramentos deve fazer parte da implementação das políticas públicas e que uma iniciativa da envergadura do Bolsa Família certamente conterá 
problemas pendentes, trata-se de uma política que conta com a aprovação da sociedade brasileira.

Por fim, o artigo demonstrou a importância de usar a opinião da sociedade como um elemento necessário de avaliação. Todavia, muitos estudos sobre o impacto de políticas públicas não consideram-na com a devida importância. No mais das vezes, a opinião se limita à visão dos beneficiários em relação a aspectos ligados à auto-estima ou a aspectos secundários. A avaliação de políticas públicas tende, na visão majoritária da área, a se limitar a aspectos econométricos, com análises comparativas sobre os impactos entre beneficiários e não-beneficiarios, em desenhos de pesquisa conhecidos como quasi-experimentos.

O presente artigo, no entanto, indica justamente o contrário: que a opinião da população pode ser um importante instrumento de avaliação de políticas públicas em seus aspectos mais substantivos: a eficácia e a eficiência. Não se trata de considerar que a opinião das pessoas represente algum tipo de verdade ou qualquer outra visão ingênua de opinião pública, mas que essas informações, com as suas devidas análises, podem fornecer importantes aspectos que permitam conhecer o impacto das políticas públicas em relação aos seus objetivos e mesmo em relação à sua efetividade.

Segundo a percepção da população, o PBF atinge os seus objetivos e parece estar sendo bem utilizado pelos seus beneficiários. Isso pode ser comprovado não apenas pelas respostas às perguntas diretas, mas pelas análises que indicam uma visão mais positiva do programa por parte daqueles que conhecem algum beneficiário. Essa diferença de percepção é um indicativo da existência de um controle social sobre o uso do benefício, na medida em que todas as respostas . sejam positivas ou negativas em relação ao programa - foram mais positivas por parte daqueles que conhecem beneficiários. É plausível supor que as pessoas de um modo geral não sejam favoráveis à fraude nas políticas públicas (e as respostas em relação às críticas avalizam essa hipótese); assim, a visão mais positiva por parte de quem diz conhecer o Programa em sua efetividade nos permite concluir que os beneficiários estão cumprindo o que deles se espera.

Esses dados permitem dizer que a sociedade brasileira apóia o PBF, não apenas pela opinião em relação aos resultados, mas principalmente por refletirem uma compreensão relativamente sofisticada sobre essa política social. Esse apoio, no entanto, não implica em uma aceitação acrítica da sua existência, mas em uma ponderação sobre ganhos e perdas. Persiste, porém, o questionamento sobre os resultados de políticas públicas com distribuição direta de renda no longo prazo, se permitem a ruptura com o ciclo vicioso da pobreza, e a saída permanente dos beneficiários dessa situação, ou se constitui apenas um paliativo de curto prazo. A resposta a essa pergunta somente poderá ser dada à medida que mais estudos forem feitos, e é um grande desafio para a pesquisa acadêmica. 


\section{Referências Bibliográficas}

CASTEL, R. As metamorfoses da questão social: uma crônica do salário. Petrópolis, Rio de Janeiro: Vozes, 1998.

CASTRO, H. C. de O. de; SCHMIDT, B. V. M.; WALTER, D. N. C.; CAMPOS, M. I. M. T., TÂNIA M. de A. Avaliação nacional do Programa Bolsa Escola Federal. Brasília, MEC. Relatório de Pesquisa, 2003.

CLEMENTE, I. "Programas assistenciais podem ser eficientes contra a pobreza. Mas, na dose errada, eles geram milhões de dependentes". Revista Época, n ${ }^{\circ} 427$, 24/07/2006. Disponível em:

<http://revistaepoca.globo.com/Revista/Epoca/1.EDG74845-6009,00.html> Acesso em: 23out.2008.

"Entenda como foi desmontado o esquema do 'bolsa fraude'." O Globo Online, Rio de Janeiro, 17/7/2008. Disponível em:

<http://oglobo.globo.com/rio/mat/2008/07/17/entenda_como_foi_desmontado_e squema_do_bolsa_fraude_-547291941.asp> Acesso em: 23out.2008.

HÖFLING, E. de M. "Estado e políticas (públicas) sociais". Cadernos CEDES, Campinas, v.21, $\mathrm{n}^{\circ}$ 55, nov. 2001.

HOWLETT, M. "A dialética da opinião pública: efeitos recíprocos da política pública em sociedades democráticas contemporâneas". Opinião Pública, Campinas, v.6, nº 2, 2000.

MAGALHÃES, R. "Integração, exclusão e solidariedade no debate contemporâneo sobre as políticas sociais". Cadernos de Saúde Pública, Rio de Janeiro, v.17, n 13, 2001.

MEDEIROS, M.; BRITTO, T. e SOARES, F. "Transferência de renda no Brasil". Novos Estudos, São Paulo, n 9, 2007.

MOISÉS, D. "Bolsa-Família cresce porque mantém pobreza, diz Cristovam". O Estado de S. Paulo Versão Digital Online, São Paulo, 29/3/2008. Disponível em: <http://www.estadao.com.br/nacional/not_nac147894,0.htm> Acesso em: 23 out.2008.

MOURA, P. M. G. de. "Bolsa Família: projeto social ou marketing político?". Revista Kátal, Florianópolis, v. 10, n 1, jan./jun. 2007.

OFFE, C. Problemas estruturais do Estado capitalista. Rio de Janeiro: Tempo Brasileiro, 1984. 
"MPF aponta indícios de fraude no Bolsa-Família em 62 cidades". Folha da Região, Araçatuba, 22/12/2007. Disponível em:

<http://www.folhadaregiao.com.br/noticia?81977\&PHPSESSID=2f1ef7915731d8f> Acesso em: 23out.2008.

OLIVEIRA, A. M. H. C. de.; et al. Primeiros Resultados da Análise da Linha de Base da Pesquisa de Avaliação de Impacto do Programa Bolsa Família. In: BRASIL. Ministério do Desenvolvimento Social e Combate à Fome. Avaliação de políticas e programas do MDS: resultados: Bolsa Família e Assistência Social./ Ministério do Desenvolvimento Social e Combate à Fome; Secretaria de Avaliação e gestão da Informação - Brasília, DF: MDS; SAGI. (Avaliação de políticas e programas do MDS: resultados; v.2), 2007.

PINTO, A. C.; MENEZES, M. 2008. Efeito-preguiça do Bolsa preocupa. O Globo, Rio de Janeiro, 29/3/2008. Disponível em:

<http://clippingmp.planejamento.gov.br/cadastros/noticias/2008/3/29/noticia.42 0668> Acesso em: 23out.2008.

ROSANVALLON, P. A crise do Estado-providência. Goiânia: Ed. da UFG; Brasília: Ed. da UnB, 1997.

A nova questão social: repensando o Estado-providência. Brasília: Instituto Teotônio Vilela, 1998.

SENNA, M. de C. M.; SCHOTTZ, V.; MONNERAT, G. L. e MAGALHÃES, R. "Programa Bolsa Família: nova institucionalidade no campo da política social brasileira?" Revista Kátal, Florianópolis, v.10, n 1, jan./jun. 2007.

SOARES, S. S. D. "Análise de bem-estar e decomposição por fatores da queda da desigualdade entre 1995 e 2004". Econômica, Rio de Janeiro, v. 8, n 1, jun. 2006.

SOARES, F. V.; MEDEIROS, S.; OSÓRIO, M. Programas de transferência de renda no Brasil: impactos sobre a desigualdade. Texto apresentado no XXXIV Encontro Nacional de Economia, ANPEC, 5 a 8 dez., Salvador/BA 2006. Disponível em: $<w w w$.anpec.org.br/encontro_2006.htm>. Acesso em: 14out.2008.

"SUPERVISOR do Bolsa-Familia é preso em Sergipe por fraude". O Estado de S. Paulo Versão Digital Online, São Paulo, 11/11/2004.Disponível em: <http://www.estadao.com.br/arquivo/nacional/2004/not20041111p38212.htm > Acesso em: 23out.2008.

VANDERBORGHT, Y.; PARIJS, P. van. Renda básica de cidadania: fundamentos éticos e econômicos. Rio de Janeiro: Civilização Brasileira, 2006. 
YASBEK, M. C. "O programa Fome Zero no contexto das políticas sociais brasileiras". São Paulo em Perspectiva, São Paulo, v.18, n² 2, abr./jun, 2004

\section{Anexo}

\section{Descrição da Pesquisa "Percepção sobre os Programas Federais"}

A pesquisa "Percepção sobre os Programas Federais" foi realizada sob demanda da Secretaria de Comunicação da Presidência da República e executada pelo DATAUnB - Pesquisas Sociais Aplicadas. Incluiu metodologias qualitativas e quantitativas para captar a percepção na sociedade sobre programas federais nas áreas social, de educação, saúde, infraestrutura, comunicação, segurança e economia. A etapa quantitativa envolveu coleta de dados em uma amostra da população brasileira, urbana e rural, com inferência de nível regional. A amostra totalizou 6001 entrevistas domiciliares em 214 municípios de 25 unidades da federação brasileiras. O esquema amostral foi por conglomerados em dois estágios em cada uma das cinco regiões, cujas amostras foram de 1200 unidades. Um dos principais objetivos foi avaliar o quanto os programas eram conhecidos pelo nome ou por suas funções e em que medida a população considerava que os respectivos objetivos estavam sendo atingidos. O programa federal analisado com maior detalhe foi o Bolsa Família

Henrique Carlos de Oliveira de Castro · henrique@unb.br

Maria Inez Machado Telles Walter·minez@unb.br

Cora Maria Bender de Santana -corambs@gmail.com

Michelle Conceição Stephanou·mistephanou@uol.com.br

Recebido para publicação em dezembro de 2008.

Aprovado para publicação em abril de 2009. 